
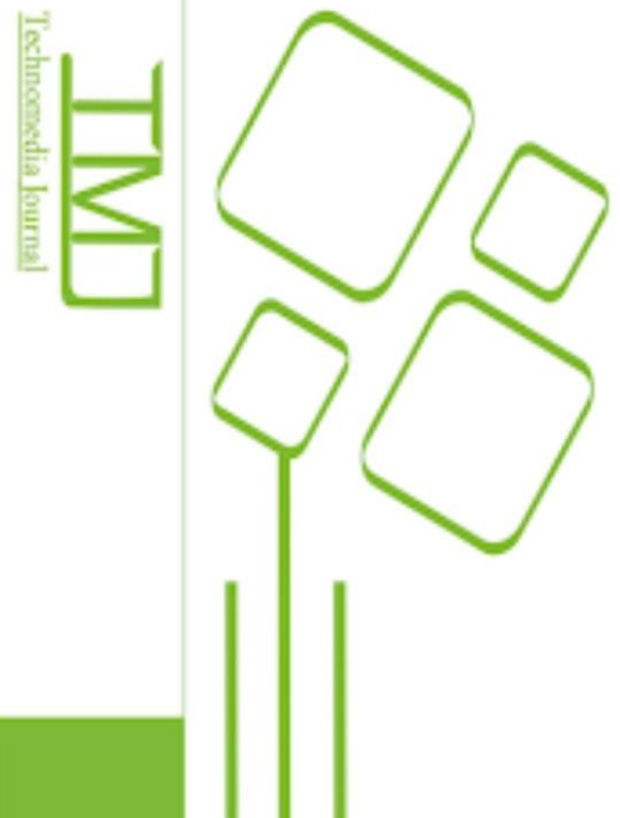

E-ISSN: 2528 - 6544

P-ISSN: 2620 - 3383

Vol.1 No.1 Agustus 2016

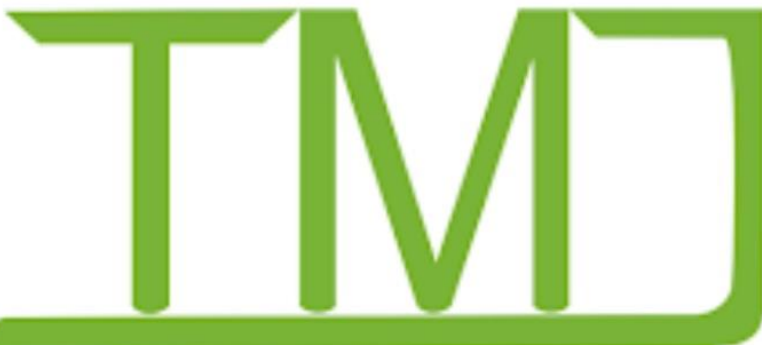

Technomedia Journal

iLearning Journal Center (iJC)

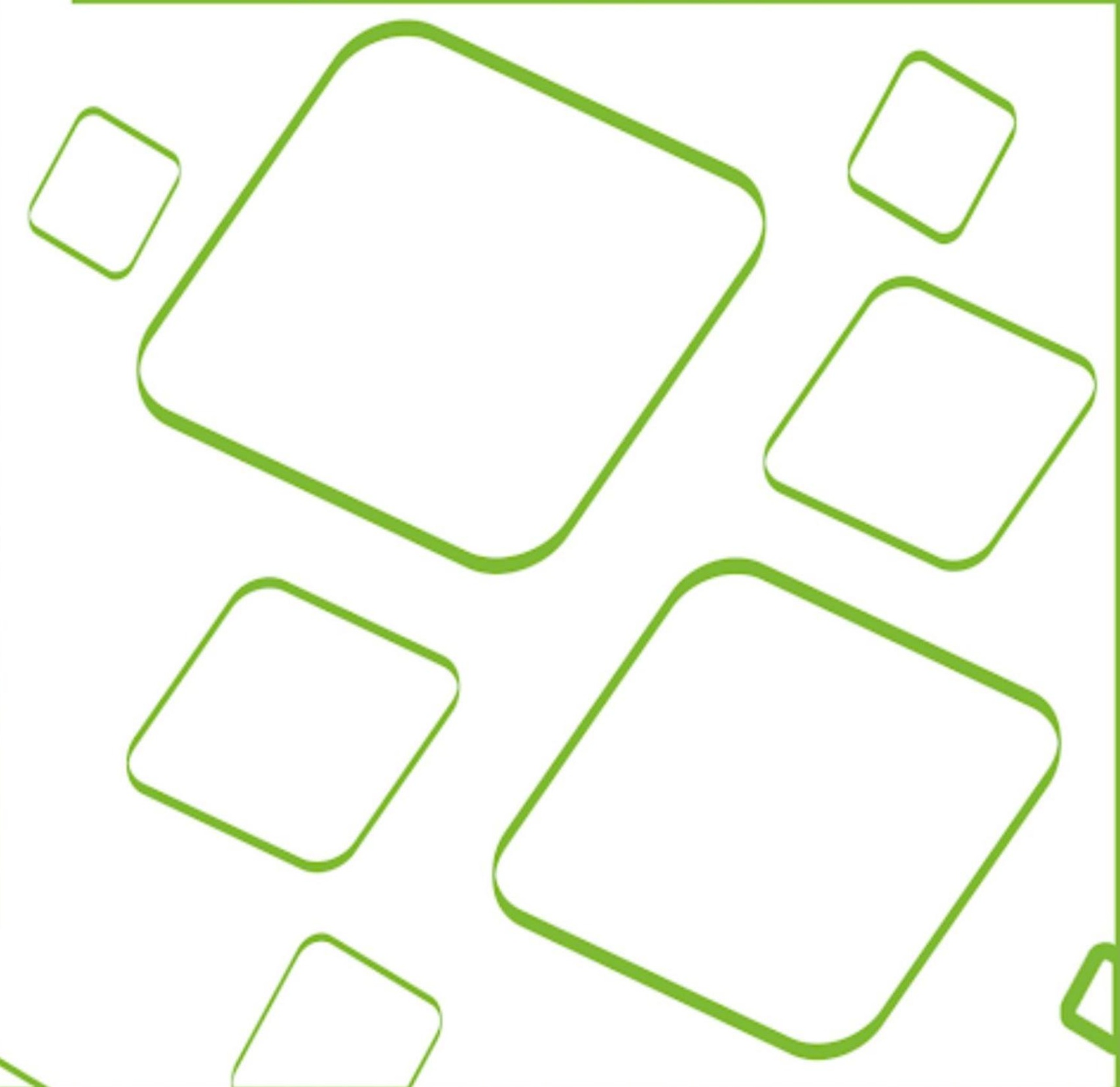


Technomedia Journal adalah jurnal elektronik ilmiah yang diterbitkan oleh iJC (iLearning Journal Center). Technomedia Journal terbit tiga kali dalam satu tahun Februari, Juni, dan Oktober yang berisi artikel hasil penelitian dalam bidang Sistem Informasi dan Teknologi Informatika.

\section{Ketua Redaksi :}

Ir. Untung Rahardja.,M.T.I

Sekretaris Redaksi :

Indri Handayani, S.Kom., M.T.I

\section{Mitra Bestari :}

Prof. Ir. Joko Lianto Buliali, M.Sc.,Ph.D

Prof. Dr.rer.nat. Achmad Benny Mutiara, SSi, SKom

Prof. Dr. Moedjiono. MSc

Dr. Winarno

Dr. Harco Lesly

Panca Oktavia Hadi Putra, Bsc., M.Sc.,

Henderi, M.Kom

Dr. Ir. I. Joko Dewanto, MM

Dr. Ir. Sudatyono, S.Pd., M.Pd

\section{Editor/ Layout : \\ Maulana Sani \\ Yuli Widiastuti}

\section{Bendahara:}

Eka Purnama Harahap, S.Kom

\section{Alamat Redaksi :}

Jl. Jendral Sudirman No 40, Cikokol - Tangerang Tel / fax : (021)5529692

Email: ijc@ raharjagroups.info atau ijc@ raharja.info 


\section{Dewan Redaksi}

Puji dan syukur kehadirat Allah SWT atas karunia dan lindunganNya sehingga TMJ terbitan Vulume 1 Nomor 1 Edisi Oktober 2016 dapat diterbitkan tepat waktu.

Penerbitan jurnal ini dimaksudkan sebagai media informasi ilmiah dibidang ilmu komputer yang diharapkan dapat membantu para dosen dan mahasiswa dalam menginformasikan hasil penelitian dan kajian ilmiah lainnya kepada berbagai komunitas ilmiah diseluruh Indonesia.

Penerbitan jurnal Volume 1 Nomor 1 Edisi Oktober 2016 berisikan 10 artikel yang mencakup bidang Ilmu Komputer, Teknologi Informasi, Sistem Informasi, walaupun tidak seluruhnya merupakan hasil penelitian diharapkan dapat bermanfaat bagi pembacanya. Puji syukur kehadirat Allah SWT karena 10 artikel adalah dari STMIK dan AMIK Raharja.

Jurnal ini diterbitkan dengan memuat artikel Fitur Form Emailer Dalam Memaksimalkan Penggunaan Rinfo Form Pada Perguruan Tinggi, Implementasi Fgr (First Generation Resources) Dengan Menggunakan Mailchimp Sebagai Sarana Informasi Di Perguruan Tinggi, Optimalisasi Penerapan Rooster Berbasis Osticket Untuk Meningkatkan Mutu Pelayanan, Penerapan Rinfosheet Sebagai Media Penunjang Pembuatan Laporan Untuk Mahasiswa, Penerapan Rinfosheet Sebagai Media Penunjang Pembuatan Laporan Untuk Mahasiswa, Optimalisasi Viewboard Rhjfox Berbasis Bootstrap Sebagai Sistem Penunjang Keputusan, Penerapan Viewboard Go+ Berbasis Yii Sebagai Media Monitoring Pembayaran Mahasiswa, Pemanfaatan Rinfo Form Sebagai Media Pembuatan Kuesioner Dalam Proses Pengumpulan Data Pada Perguruan Tinggi, Pemanfaatan Google Scholar Dan Citation Dalam Memenuhi Kebutuhan Pembuatan Skripsi Mahasiswa Pada Perguruan Tinggi, Penerapan Mata Uang Armo (Airzone-Mall Money) Pada Marketplace Airzone-Mall Sebagai Inovasi Pembelajaran Internet Dan E-Commerce, Media Audio Visual Menggunakan Videoscribe Sebagai Penyajian Informasi Pembelajaran Pada Kelas Sistem Operasi.

Tidak lupa pula pada kesempatan ini kami mengundang para pembaca untuk mengirimkan naskah hasil penelitian kepada kami. Dan tidak lupa pula kami mengucapkan banyak terimakasih kepada semua pihak yang telah membantu penerbitan jurnal ini.

Tangerang, 31 Oktober 2016

Redaksi 


\section{Daftar Isi}

1. FITUR FORM EMAILER DALAM MEMAKSIMALKAN PENGGUNAAN RINFO FORM PADA PERGURUAN

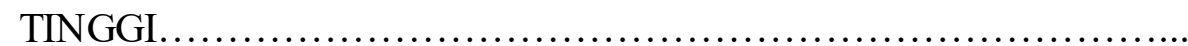
Indri Handayani, Qurotul Aini, Reza Alfiansah

2. IMPLEMENTASI FGR (FIRST GENERATION RESOURCES) DENGAN MENGGUNAKAN MAILCHIMP SEBAGAI SARANA INFORMASI DI PERGURUAN TINGGI. Qurotul Aini, Indri Handayani, Nuril Huda

3. OPTIMALISASI PENERAPAN ROOSTER BERBASIS OSTICKET UNTUK MENINGKATKAN MUTU PELAYANAN. Untung Rahardja, Khanna Tiara, Ria Utami

4. PENERAPAN RINFOSHEET SEBAGAI MEDIA PENUNJANG PEMBUATAN LAPORAN UNTUK MAHASISWA Khanna Tiara, Erlita Rasdiana, Nursam Somantri

5. OPTIMALISASI VIEWBOARD RHJFOX BERBASIS BOOTSTRAP SEBAGAI SISTEM PENUNJANG KEPUTUSAN...... Untung Rahardja, Khanna Tiara, Maya Ima Erviani

6. PENERAPAN VIEWBOARD GO+ BERBASIS YII SEBAGAI MEDIA MONITORING PEMBAYARAN MAHASISWA .............. $\quad 65-77$ Khanna Tiara, Tuti Nurhaeni, Ika amalia

7. PEMANFAATAN RINFO FORM SEBAGAI MEDIA PEMBUATAN KUESIONER DALAM PROSES PENGUMPULAN DATA PADA PERGURUAN TINGGI Erlita Rasdiana, Fadil Nur Muhamad, Ridwan Kurniaji

8. PEMANFAATAN GOOGLE SCHOLAR DAN CITATION DALAM MEMENUHI KEBUTUHAN PEMBUATAN SKRIPSI MAHASISWA PADA PERGURUAN TINGGI....................... Untung Rahardja, Khanna Tiara, Iis Ariska Rosalinda

9. PENERAPAN MATA UANG ARMO (AIRZONE-MALL MONEY) PADA MARKETPLACE AIRZONE-MALL SEBAGAI INOVASI PEMBELAJARAN INTERNET DAN E-COMMERCE. Qurotul Aini, Untung Rahardja, Dita Lintang Nurani

10. MEDIA AUDIO VISUAL MENGGUNAKAN VIDEOSCRIBE SEBAGAI PENYAJIAN INFORMASI PEMBELAJARAN PADA KELAS SISTEM OPERASI. 


\title{
Penerapan Mata Uang Armo (AirzonE-Mall Money) Pada Marketplace AirzonE-Mall Sebagai Inovasi Pembelajaran Internet dan E-commerce
}

\author{
Qurotul Aini ${ }^{1}$ \\ Untung Rahardja ${ }^{2}$ \\ Dita Lintang Nurani ${ }^{3}$ \\ Jl. Jendral Sudirman No. 40, Modernland, Tangerang ${ }^{1,2,3}$ \\ Email: aini@raharja.info ${ }^{1}$, untung@raharja.info ${ }^{2}$, lintang@raharja.info ${ }^{3}$
}

\begin{abstract}
ABSTRAKSI
Penelitian yang bersubjek pada inovasi pembelajaran internet dan e-commerce dengan sebuah sistem marketplace online AirzonE-Mall yang dibangun menggunakan CMS (Content Managemen System). Dalam penelitian ini penulis mendapati 3 (tiga) masalah yang dihadapi pada proses pembelajaran. Sehingga didapati pemecahan masalah melalui inovasi pembelajaran yang muncul dari aktifitas di AirzonE-Mall yaitu mata uang khusus bagi user yang disebut dengan Armo (AirzonE-Mall Money). Armo merupakan mata uang virtual yang didapatkan dari aktifitas user pada komunitas online ZPreneur yang menaungi AirzonE-Mall sebagai media pembelajaran e-commerce. Proses pembelajaran yang sebelumnya berjalan dengan 3 (tiga) alur monoton dapat dibuat menjadi alur yang menarik. Dilakukan 11 (sebelas) literature review sebagai acuan penulis dalam mengembangkan sistem AirzonEMall. Selanjutnya diterapkan 15 (lima belas) strategi untuk menunjang pengembangan sistem AirzonE-Mall. Implementasi yang dilakukan penulis yaitu melalui aktifitas yang dilakukan mahasiswa pada ZPreneur yang diatur sedemikian rupa dengan menerapkan sistem gamifikasi. Diharapkan dengan inovasi pembelajaran ini menjadi hal menarik bagi mahasiswa dalam proses pembelajaran internet dan e-commerce.
\end{abstract}

Kata kunci: AirzonE-Mall, Armo, Inovasi Pembelajaran

\begin{abstract}
Be subject research on learning innovation internet and e-commerce with an online marketplace system AirzonE-Mall which was built using a CMS (Content Management System). In this study the authors found three (3) problems encountered in the learning process. Thus found solving through learning innovations arising from activities in AirzonEMall is a special currency for the user who called the ARMO (AirzonE-Mall Money). ARMO is the virtual currency earned from user activity on an online community ZPreneur that houses AirzonE-Mall as a learning medium of e-commerce. The learning process previously run with 3 (three) monotonous groove can be made into an attractive flow. Do 11 (eleven) literature review as a reference the author in developing the system AirzonE-Mall. Furthermore applied 15 (fifteen) strategy to support the development of systems AirzonEMall. Implementation by the author is through activities done by the students on ZPreneur arranged in such a way by applying gamification system. Learning innovation is expected to be a matter of interest to the student in the learning process of the Internet and e-commerce.
\end{abstract}

Keywords: AirzonE-Mall, Armo, Learning Innovation

114 | Qurotul, Untung, Dita - Penerapan Mata Uang Armo... 


\section{PENDAHULUAN}

Era globalisasi yang kian hari kian berkembang memberikan dampak perubahan pada semua aspek bidang kehidupan, terutama bidang pendidikan. Kebudayaan global menjadi istilah yang muncul seiring dengan modernitas dalam proses globalisasi yang memberikan banyak ruang untuk inovasi baru menawarkan berbagai kreatifitas yang membuat dunia pendidikan semakin menarik bagi siapapun yang masuk ke dalam lingkupnya. Bagi para pendidik dan pimpinan lembaga pendidikan di Indonesia, era ini tentu saja memberikan banyak kesempatan untuk bangkit mensejajarkan dirinya dengan negara-negara lain di dunia, sekaligus ancaman, atau setidaknya tantangan. Bagi Perguruan Tinggi Raharja, kebudayaan global merupakan tantangan yang harus dihadapi dengan strategi yang dibangun bersama antar pendidik dan peserta didik.

Kutipan dari Dekan FE UNY (Universitas Negeri Yogyakarta), Dr. Sugiharsono, M.Si secara umum pendekatan pembelajaran bisa dikelompokkan menjadi 2 (dua) yaitu pendekatan ekspositori (expository approach) dan penedekatan inkuiri (inquiry approach). Pendekatan ekspositori merupakan pendekatan pembelajaran yang bersifat "teacher centered" dimana peserta didik cenderung berperan sebagai objek belajar, sedangkan pendidik berperan sebagai "agen" pengetahuan yang akan ditransfer kepada peserta didik. Interaksi yang terjadi cenderung "one way interaction", sampai dengan "two ways interaction" dengan metode pembelajaran adalah ceramah, dengan kemungkinan variasi tanya jawab. Sementara itu, pendekatan inkuiri yang juga sering disebut pendekatan discovery merupakan pendekatan pembelajaran yang bersifat "student centered" dimana peserta didik cenderung berperan sebagai subjek belajar, sedangkan pendidik lebih berperan sebagai fasilitator dan sewaktu-waktu bisa berperan sebagai konduktor (penengah dan penyelaras). Interaksi yang terjadi cenderung "multyways interaction", dengan metode pembelajaran yang digunakan antara lain, problem solving, diskusi, tanya-jawab, penugasan, studi lapangan, simulasi, dan demonstrasi. Dan pada era globalisasi dan teknologi informatika saat ini, pendekatan inkuiri lebih cocok diterapkan karena memiliki 9 (sembilan) metode pembelajaran yang dapat membantu inovasi dalam proses pembelajaran dapat diaplikasikan.
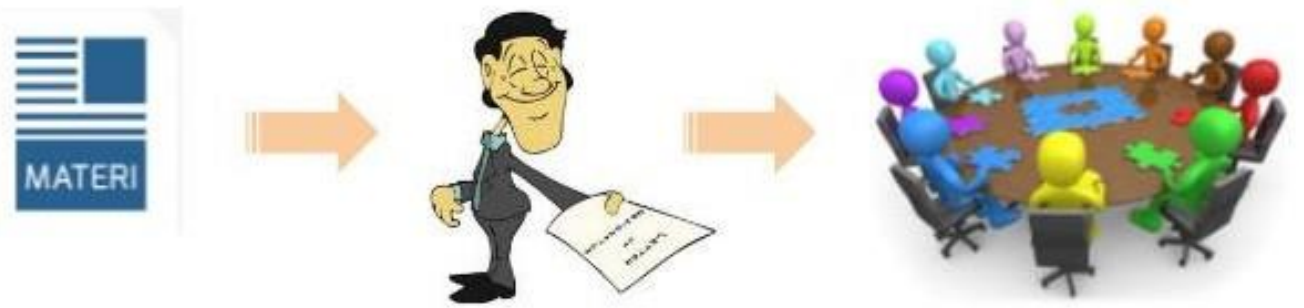

Gambar 1. Alur proses pembelajaran berjalan

Proses kegiatan belajar mahasiswa yang berjalan saat ini masih berpatok pada pemberian dan penjelasan materi oleh dosen. Lalu dosen memberikan tugas kepada mahasiswa, kemudian mahasiswa melakukan diskusi untuk mendapatkan jawaban tugas dari dosen. Proses belajar yang dipenuhi dengan teori seringkali membuat mahasiswa merasa jenuh, sehingga dibutuhkan transformasi pembelajaran yang dapat memberikan inovasi pada proses pembelajaran. Inovasi dalam hal pendidikan harus dilakukan secara bersama untuk mendapatkan hasil mutu yang sesuai dan menetap. Dalam lingkup kecil seperti sebuah instansi pendidikan, perlu ada kerjasama yang baik antar tenaga pendidik dan peserta didik 
untuk menerima inovasi yang ditetapkan dan kemudian dijalankan demi mencapai hasil mutu pendidikan yang diinginkan.

Kaitan antara globalisasi dan pendidikan, dikarenakan ilmu pengetahuan berkembang dengan pesat dalam proses globalisasi yang merupakan dasar dari globalisasi ekonomi dan politik di dunia ini. Untuk itu pendidikan sangat penting dalam mewujudkan masyarakat masa depan yang berdasarkan ilmu pengetahuan, melalui pendidikan proses transmisi serta pengembangan ilmu pengetahuan akan terjadi. Mahasiswa sebagai bagian dari sumber daya alam yang mempunyai sumbangan dalam memajukan bangsa dituntut untuk memiliki kesadaran untuk menggali informasi, ilmu pengetahuan dan membekalkan diri dengan kapasitas keilmuan yang tinggi.

Upaya yang ditempuh oleh Perguruan Tinggi Raharja untuk membantu mahasiswa dalam menggali informasi dan ilmu pengetahuan dengan menggabungkan beberapa hal pendukung agar inovasi baru dapat terwujud. Beberapa hal pendukung mencakup sistem yang sudah berjalan sebelumnya yaitu marketplace yang dibangun dengan menggunakan CMS (Content Management System) dan penerapan konsep yang ada pada game yang diterapkan pada konteks non-game, yang disebut sebagai gamifikasi. Dari hal pendukung tersebut membuat inovasi dapat berjalan yang kemudian memberikan ketertarikan lebih dari mahasiswa dalam proses pembelajaran. Terutama proses pembelajaran internet dan $e$ commerce, dimana pembelajaran internet dan e-commerce bertujuan untuk melatih mahasiswa lebih aktif menyesuaikan arus deras dunia internet, tekun dan independen dalam mengamati perkembangan dan memecahkan penemuan, kreatif dan inovatif agar bisa bertahan menjadi pribadi yang unggul melalui pembelajaran dunia e-commerce. Dengan sudah memiliki ketertarikan dalam proses belajar, mahasiswa akan lebih mudah menerima pembelajaran yang diterima maupun dijalankan sehingga hal tersebut dapat memperbaiki mutu pembelajaran yang tentu memberikan dampak pasti pada mutu mahasiswa.

\section{PERMASALAHAN}

Penelitian ini dilakukan untuk mendeskripsikan inovasi yang tercipta dalam kegiatan pembelajaran mahasiswa melalui sebuah project marketplace AirzonE-Mall. Dari latar belakang di atas, didapatkan temuan yang berkaitan dengan proses belajar mahasiswa yang sudah diuraikan pada pendahuluan. Dimana kegiatan belajar yang berjalan seringkali membuat mahasiswa merasa jenuh, sehingga dibutuhkan transformasi pembelajaran yang dapat memberikan inovasi pada proses pembelajaran.

Inti pada proses pembelajaran adalah untuk mendapatkan penilaian terhadap mutu mahasiswa. Maka untuk mendapatkan mutu mahasiswa yang baik, harus membuat suasana pembelajaran yang mendukung materi yang diterima oleh mahasiswa baik. Sesuai dengan perkembangan karakteristik psikologi mahasiswa saat ini yang cenderung ingin bebas berapresiasi sebagai subjek belajar, bukan lagi sebagai objek belajar. Mahasiswa cenderung menginginkan perlakuan pembelajaran yang lebih bebas, menantang, menyenangkan, dan menggairahkan. Di sisi lain, adanya perbedaan kemampuan, bakat, dan minat siswa menuntut perlakuan pembelajaran yang bervariasi dan dapat diterima oleh yang berbeda karakteristiknya. Oleh karena itulah para pelaku pendidikan dituntut untuk bisa menemukan dan mengaplikasikan inovasi pembelajaran dengan berbagai metode dan strategi pembelajaran, serta media dan sumber belajar yang sesuai dengan kebutuhan. 
AirzonE-Mall merupakan sebuah marketplace online yang dibangun dengan menggunakan CMS (Content Management System) bertujuan sebagai media pembelajaran mahasiswa dalam dunia technopreneur. AirzonE-Mall sendiri berada di bawah naungan sebuah komunitas online yaitu ZPreneur, yang menjadi wadah bagi para mahasiswa aktif terutama Pribadi Raharja berkumpul untuk bertukar informasi dan berdiskusi. Hubungan AirzonE-Mall dengan ZPreneur seperti sebuah permainan monopoli, dimana kita perlu mengocok dadu untuk mendapatkan mata dadu dengan jumlah angka yang membuat kita bisa berjalan lalu melewati berbagai proses permainan yang dapat membuat kita memiliki uang sehingga kita dapat membeli hal yang diinginkan pada papan monopoli. Seperti halnya AirzonE-Mall yang diibaratkan papan monopoli, didalamnya terdapat banyak hal yang dapat dibeli dengan point yang sudah didapatkan dari aktifitas di ZPreneur yang disebut Armo. Dengan Armo kita dapat melakukan transaksi di AirzonE-Mall dengan syarat dan ketentuan yang diberlakukan seperti Armo sama dengan Rupiah, Armo hanya dapat berlaku pada store dengan kategori jasa.

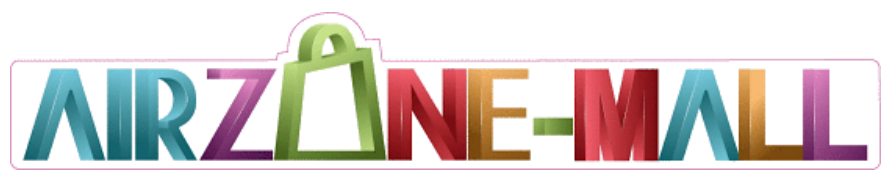

Gambar 2. Logo AirzonE-Mall

Maka berdasarkan uraian tersebut, dapat ditarik rumusan permasalahan sebagai berikut:

1. Bagaimana penerapan Armo pada sistem AirzonE-Mall dapat membuat aktifitas pembelajaran lebih menarik?

2. Bagaimana menarik minat mahasiswa Perguruan Tinggi Raharja untuk dapat berkontribusi di AirzonE-Mall?

3. Bagaimana sistem marketplace AirzonE-Mall mampu menjadi wadah menarik untuk pembelajaran internet dan e-commerce?

\section{LITERATURE REVIEW}

Banyak penelitian yang dilakukan sebelumnya mengenai sistem pembelajaran maupun penjualan online serta penelitian lain yang berkaitan. Dalam upaya mengembangkan dan menyempurnakan sistem AirzonE-Mall yang menunjang pembelajaran technopreneur, maka penulis melakukan studi pustaka (literature review) sebagai salah satu dari penerapan metode penelitian yang akan dilakukan. Diantaranya yaitu:

1. Penelitian yang dilakukan oleh Panca O. Hadi Putra dan Zainal Hasibuan pada tahun 2015 dengan judul 'E-Business Framework Small and Medium Entreprises: A

Critical Review". Penelitian ini menjelaskan tentang UKM (Usaha Kecil Menengah) yang dianggap sebagai pendorong perekonomian suatu negara, terutama negara berkembang. Dewasa ini berkembang penerapan internet pada kegiatan bisnis yang disebut dengan e-business, yang membuat UKM (Usaha Kecil Menengah) harus bisa beradaptasi dengan hal tersebut. Maka adanya penelitian ini bermaksud untuk memberikan pemahaman lebih perihal e-business agar UKM (Usaha Kecil Menengah) dapat bersaing di pasar online dan mendapat keuntungan dari transaksi bisnis yang dilakukan. 
2. Penelitian yang dilakukan oleh Caesar Fattah Citra Dewantara pada tahun 2015 dengan judul "Analisis Dampak Penggunaan Situs Bukalapak Terhadap Perilaku Pembelian Pada Komunitas Samarinda Photographer". Penelitian ini menjelaskan tentang perilaku konsumen online yang muncul dari hasil penelitian, yaitu perilaku pembelian terencana dan pembelian tidak terencana. Perilaku konsumen juga dipengaruhi oleh motivasi dalam melakukan pembelian yang didasari oleh Convenience Shoppers atau factor kenyamanan yang tercipta karena tampilan, kemudahan akses dan transaksi, selain itu perilaku konsumen juga dipengaruhi oleh Variety Seeker yaitu dimana konsumen melakukan pembelian dengan adanya dorongan oleh motivasi keinginan untuk mencari perbandingan dan yang terakhir yaitu Balanced Buyer yaitu dimana perilaku konsumen terbentuk karena adanya keseimbangan antara dorongan dan kenyamanan.

3. Penelitian yang dilakukan oleh Viktor Nicolas Nore pada tahun 2013 dengan judul 'Perancangan Sistem Informasi Penjualan dan Pemesanan Produk Berbasis Web Studi Kasus: CV. Richness Development Bandung”. Penelitian ini menjelaskan bahwa $\mathrm{CV}$. Richness Development dengan produksinya yaitu pakaian, memfokuskan pada pelayanan serta kualitas barang yang dihasilkan secara baik. Namun, pada praktik lapangan konsumen masih sulit untuk mengetahui produk yang diinginkan dan mencari media promosi. Sehingga menyebabkan penurunan target penjualan pada CV. Richness Development. Maka adanya penelitian ini ditujukan untuk merancang sebuah sistem informasi penjualan dan pemesanan pakaian berbasis web, mengetahui implementasi sistem serta mengetahui analisis dan pengujian program pada $\mathrm{CV}$. Richness Development.

4. Penelitian yang dilakukan oleh Budi Setiawan pada tahun 2012 dengan judul "EBusiness Yang Dilakukan Oleh SAP". Penelitian ini membahas mengenai bisnis yang dilakukan oleh salah satu perusahaan software yang telah berkembang yaitu SAP. Dalam sasaran bisnisnya, SAP membidik perusahaan besar atau pun kecil untuk menggunakan software produknya, yang dimana produk-produk yang dikeluarkan sesuai dengan kebutuhan yang menginginkan software dari SAP. Dengan adanya paradigma bisnis baru yang disebut dengan e-business atau dikenal pula dengan istilah e-commerce yang memberikan dampak besar pada praktek bisnis, setidaknya dalam hal penyempurnaan direct marketing, transformasi organisasi, dan redefinisi organisasi. Sehingga fasilitas online bisnis yang saat ini sangat bagus dalam hal service kepada para pelanggan, membuat pihak SAP biasa melayani pelanggan tanpa harus menemui pelanggan tersebut secara langsung.

5. Penelitian yang dilakukan oleh Sriyanto, Sri Hartini, dan Tino Yuka Aldila pada tahun 2011 dengan judul 'Rancang Bangun Sistem Informasi E-Commerce Untuk Jaringan Penjualan Sepeda Motor Bekas Studi Kasus: Bedagan Motor Semarang”. Penelitian ini menjelaskan metode pemasaran dan penjualan yang digunakan oleh perusahaan masih bersifat konvensional dengan hanya mengandalkan promosi melalui spanduk di depan outlet penjualan. Metode semacam ini memiliki banyak kelemahan, diantaranya keterbatasan persediaan di tiap outlet. Hal ini seringkali mengakibatkan kekecewaan konsumen bahkan hilangnya peluang penjualan. Berdasarkan kelemahan-kelemahan tersebut, maka dibuat sebuah sistem e-commerce yang dapat menampilkan semua persediaan dari berbagai jenis sepeda motor di semua cabang yang ada lengkap dengan spesifikasi dan harga produk. Sehingga penjual dan konsumen dapat mengakses 
ketersediaan sepeda motor bekas di seluruh cabang serta dapat berinteraksi secara online kapan saja dan dimana saja.

6. Penelitian yang dilakukan oleh Wahyu Aji Cahya Romadhon pada tahun 2013 dengan judul "Perdagangan Online Pada Situs Tokobagus Dalam Perspektif Tekno Ekonomi'. Penelitian ini menjelaskan tentang pola perdagangan dan interaksi sosial sehingga dapat membangun kepercayaan pengguna situs Tokobagus. Fenomena yang ada di situs Tokobagus dijelaskan melalui perspektif upaya tekno-ekonomi. Penelitian kualitatif metode yang digunakan untuk menghasilkan kegiatan pembelian dan penjualan pada situs Tokobagus. Responden yang digunakan dalam penelitian 20 orang yang semua pengguna dari situs Tokobagus. Hasil studi yang, dia tahu proses penjualan sangat mudah dan praktis dengan model perdagangan setengah dan penuh online. Dia tahu interaksi sosial pada pengguna situs dalam bentuk Asosiatif (perdagangan hubungan, persahabatan, hubungan bisnis) dan Dissociative (sengketa atau konflik). Selanjutnya pada fenomena pembelian dan penjualan melalui situs Tokobagus, dimana penggunaan teknologi internet telah menyebabkan sisi sosial-budaya yang mencakup semua bentuk hubungan antara pengguna situs Tokobagus, serta konsekuensi yang dihasilkan dari hubungan yang diperoleh. Proses pembelian dan penjualan di masyarakat akan bergeser ke arah perdagangan online.

7. Penelitian yang dilakukan oleh Untung Rahardja, Qurotul Aini dan Desi Sartika dari Perguruan Tinggi Raharja pada tahun 2014 dengan judul "Build A Business To Consumer Online Store Using Airzone Content Management System”. Penelitian ini menjelaskan pemanfaatan dari IRAN untuk mendukung sistem pelayanan mahasiswa iDuHelp! dalam memudahkan Pribadi Raharja melakukan Tridharma Perguruan Tinggi.

8. Penelitian yang dilakukan oleh Qurotul Aini, Indri Handayani dan Cahyo Anggoro Seto pada Perguruan Tinggi Raharja 2015 dengan judul "Content Management System ZPreneur In Support Of Entrepreneurship iLearning At Perguruan Tinggi Raharja". Penelitian ini menjelaskan tentang penerapan Content Management System Ecommerce ZPreneur dalam mendukung kegiatan entrepreneur mahasiswa di Perguruan Tinggi Raharja yang merupakan solusi terbaik. Sistem ZPreneur merupakan sebuah sistem e-commerce berbasis web yang mampu membantu mahasiswa dalam melakukan kegiatan entrepreneur.

9. Penelitian yang dilakukan oleh Elizaandyni Ginting dengan judul "Aplikasi Penjualan Berbasis Web (E-Commerce) Menggunakan Joomla Pada Mutiara Fashion". Penelitian ini dilakukan untuk perbaikan sistem penjualan awal yang masih menggunakan jejaring sosial Facebook menjadi website, dimana sebelumnya hanya menampilkan foto atau gambar produk dan harga saja. Sistem website pada Mutiara Fashion tentu memudahkan konsumen dan masyarakat umum untuk mengetahui informasi produk yang ada di Mutiara Fashion. Dengan hanya membuka website, informasi produk dari Mutiara Fashion dapat dilihat dengan baik dan jelas. Aplikasi website Mutiara Fashion dibangun dengan menggunakan Joomla! yang merupakan CMS untuk membaca bahasa pemrograman website, MySQL untuk database, dan PHPMyAdmin sebagai tools untuk mengelola database berbasis web. (Elizaandyni Ginting : 2013). 
10. Penelitian yang dilakukan oleh Aprizal dan Nurdiansah dari STMIK Dipanegara Makassar pada tahun 2015 dengan judul "Perancangan Aplikasi E-Commerce Pada Kalingga Jati Mebel Furniture". Penelitian ini membahas mengenai sistem yang digunakan pada toko Kalingga Jati sebagai media untuk mempermudah proses komunikasi dan transaksi antara penjual dan pembeli.

Dari 10 (sepuluh) literature review yang telah dijabarkan di atas, telah banyak penelitian yang membahas pemanfaatan kemajuan teknologi dalam dunia bisnis. Namun belum ada peneliti yang secara khusus membahas tingkat efektifitas dan efisiensi marketplace terhadap suatu toko online.

\section{PEMECAHAN MASALAH}

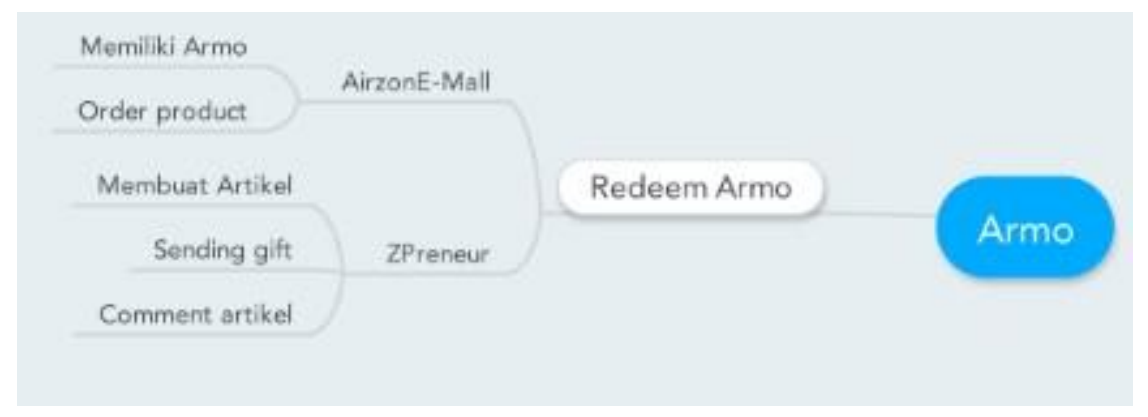

Gambar 3. Mindmapping Armo

Sebagai strategy untuk mengaplikasikan inovasi pembelajaran yang sudah tercipta sebagai media dan sumber belajar yang sesuai dengan kebutuhan mahasiswa, Perguruan Tinggi Raharja menciptakan sebuah marketplace online yang diberi nama AirzonE-Mall. Diharapkan marketplace online AirzonE-Mall dapat menjadi metode pembelajaran technopreneur bagi mahasiswa yang dapat memberikan ruang belajar baru.

\section{Contribute More! ZF'reneur}

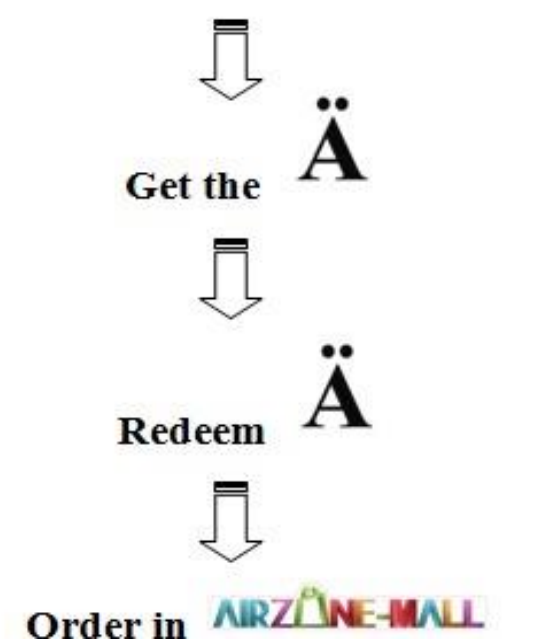

Gambar 4. Alur Armo 
Dimana melalui AirzonE-Mall, terbentuk inovasi pembelajaran baru yaitu Armo yang diaplikasikan beriringan dengan konsep gamifikasi yang membuat ruang belajar technopreneur yang bebas dan ekspresif bagi mahasiswa. Konsep gamifikasi dapat memberikan dorongan kepada mahasiswa untuk beraktifitas lebih dalam proses belajar untuk mendapatkan banyak Armo yang memberikan keuntungan baik dari nilai untuk proses pembelajaran maupun keuntungan dapat berbelanja di AirzonE-Mall dengan menggunakan Armo.

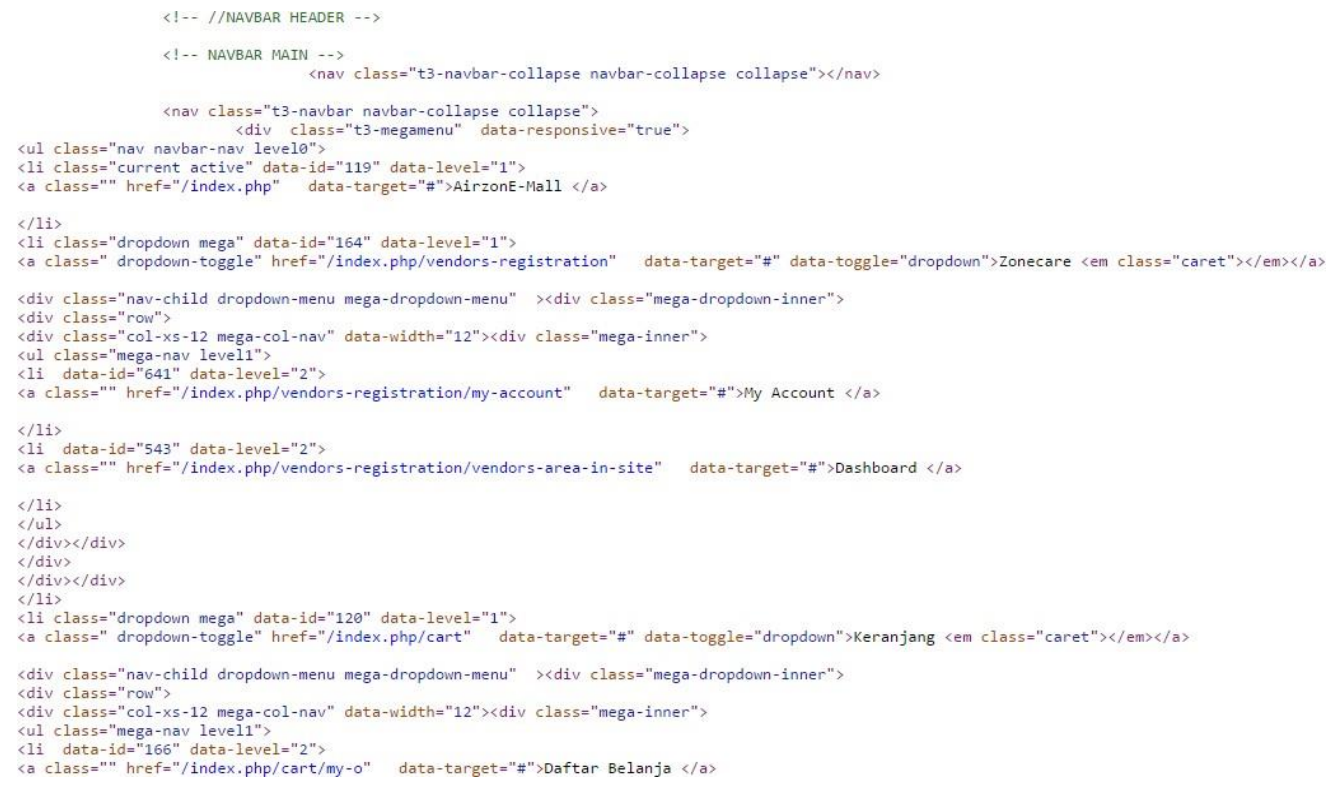

Gambar 5. Coding sistem AirzonE-Mall

\section{IMPLEMENTASI}

Berikut adalah tampilan dari alur Armo mulai dari komunitas online ZPreneur hingga dapat digunaka pada marketplace online AirzonE-Mall.

1. ZPreneur - My profile, untuk melihat jumlah Armo yang dimiliki di ZPreneur.

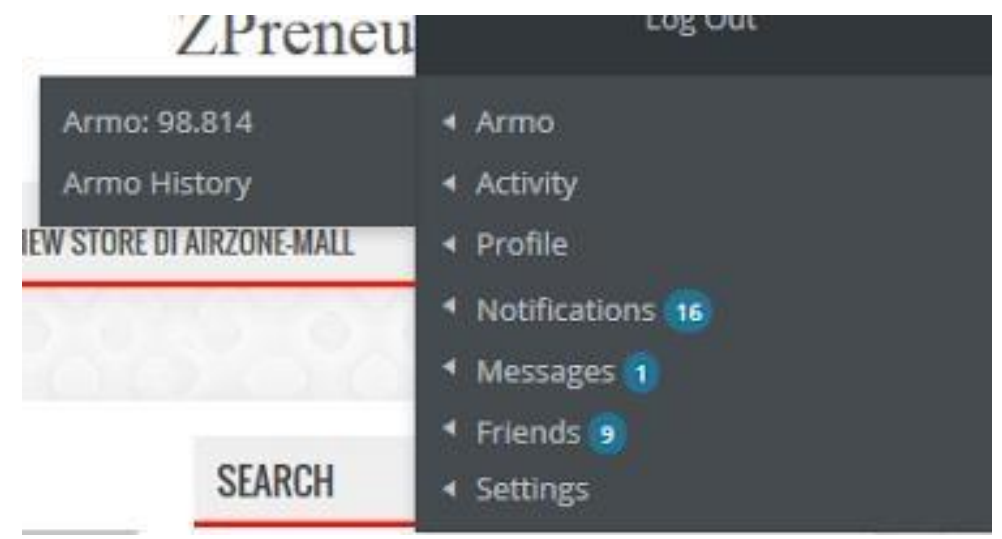

Sumber: zpreneur.org

Gambar 6. Tampilan My Profile - ZPreneur 
2. Redeem Armo, untuk memindahkan Armo yang dimiliki di ZPreneur ke AirzonE-Mall agar dapat digunakan untuk bertransaksi di AirzonE-Mall pada toko atau produk yang berkategori jasa.

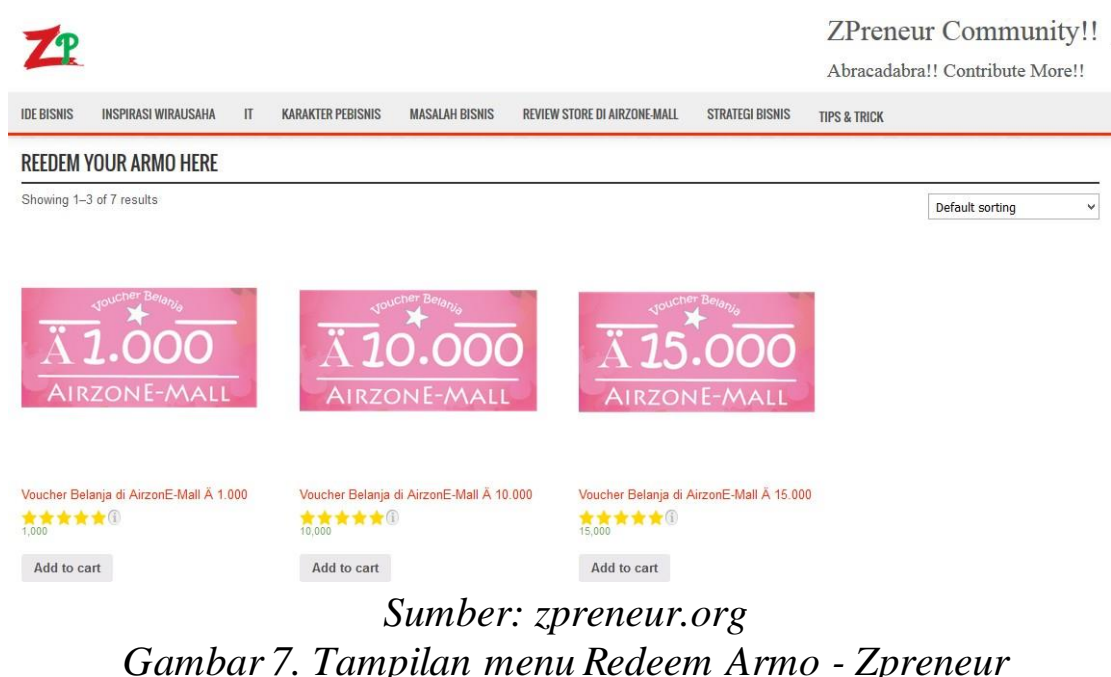

3. AirzonE-Mall - Zonecare - My Account, untuk melihat jumlah Armo yang dimiliki di AirzonE-Mall.

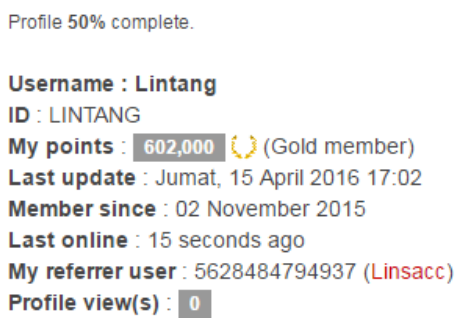

Sumber: airzone.zpreneur.org

Gambar 8. Tampilan My Profile AirzonE-Mall

Jumlah Armo sebelum digunakan bertransaksi.

\section{Penggunaan Armo di AirzonE-Mall}

1. Pilih toko atau produk yang berkategori jasa, sebagai contoh toko FGR Service yang memberikan jasa scan plagiat. 


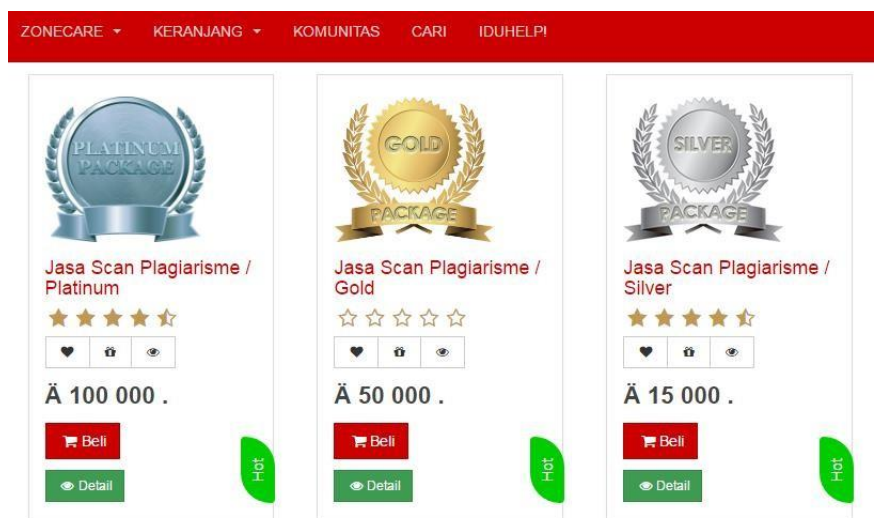

Sumber: airzone.zpreneur.org

Gambar 9. Tampilan product dari toko FGR Service

2. Beli, untuk melakukan pembelian. Lihat quantity barang dan total harga dari pembelian, jika sudah sesuai Proceed to Checkout.

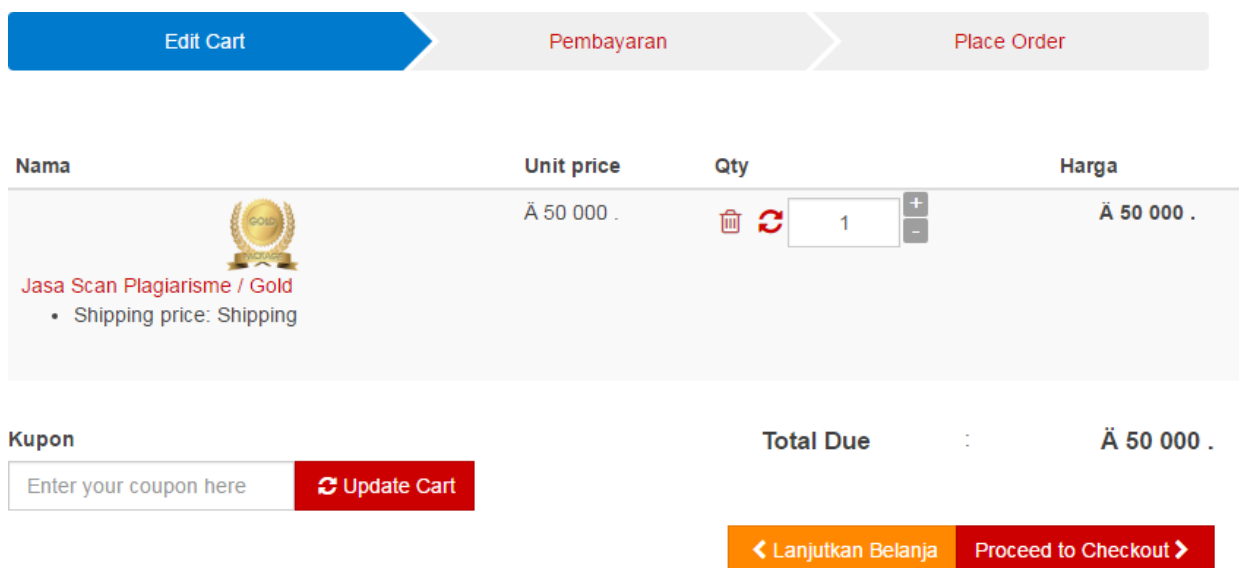

Sumber: airzone.zpreneur.org

Gambar 10. Tampilan List Cart

3. Pay with Armo, pemilihan metode pembayaran dengan menggunakan Armo.

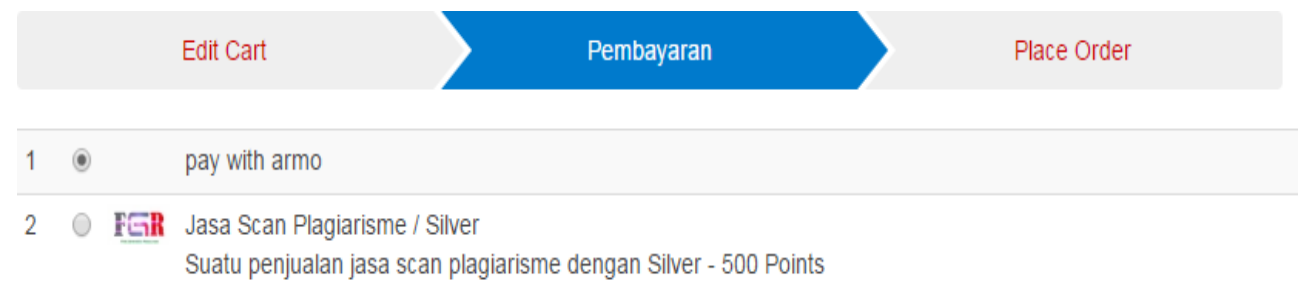

Sumber: airzone.zpreneur.org

Gambar 11. Tampilan pilihan metode pembayaran 
4. Setelah berhasil, pembelian akan masuk ke List Order. Maka barang yang telah di order akan diproses oleh vendor (pemilik toko) dan diterima oleh customer (pembeli).

\section{Saya Orders}

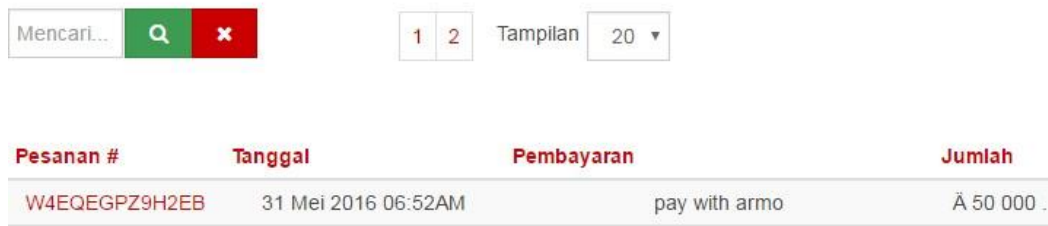

Sumber: airzone.zpreneur.org

Gambar 12. Tampilan List Order

5. Sehingga Armo berkurang otomatis setelah digunakan untuk bertransaksi.

\section{Dita Lintang}

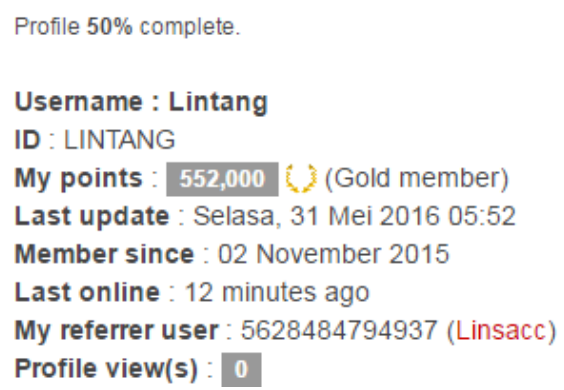

Sumber: airzone.zpreneur.org

Gambar 13. Tampilan My Profile AirzonE-Mall

Jumlah Armo sudah berkurang setelah melakukan transaksi.

\section{KESIMPULAN}

Penerapan Armo pada sistem AirzonE-Mall terbukti dapat membuat aktifitas pembelajaran menjadi lebih menarik karena penerapan Armo memberi dorongan kepada mahasiswa untuk Contribute More di Zpreneur dengan alur yang sudah ditentukan untuk mendapatkan nilai dan juga jumlah Armo yang diinginkan sesuai dengan product yang ingin di order oleh mahasiswa itu sendiri di marketplace AirzonE-Mall.

Sistem gamifikasi yang diterapkan untuk mendapatkan Armo menjadi hal yang dapat menarik minat mahasiswa Perguruan Tinggi Raharja untuk dapat berkontribusi di AirzonEMall dengan Armo yang di dapatkan. Mahasiswa dapat melakukan transaksi untuk 
mendapatkan product yang diinginkan maupun dapat membuat toko untuk melakukan kegiatan promosi dan jual beli.

Sistem marketplace AirzonE-Mall mampu menjadi wadah menarik untuk pembelajaran internet dan e-commerce dengan sistem yang memiliki banyak fungsi dari fasilitas-fasilitas yang tersedia. Hal tersebut tentu menjadi hal menarik bagi mahasiswa dalam proses pembelajaran internet dan e-commerce.

\section{DAFTAR PUSTAKA}

[1] Gumilang, AS Panji. 2013. Globalisasi dan Pendidikan. Diakses pada tanggal 29 April 2016. Tersedia di http://www.tokohindonesia.com/publikasi/article/322-opini/4184globalisasi-dan-pendidikan

[2] J. Soedjati Djiwandono. Menggagas Paradigma Baru Pendidikan, Yogyakarta:

Kanisius 2000 hal 103 (disampaikan pada seminar bertajuk "Quo Vadis Pendidikan di Indonesia", 21 - 23 Agustus 2000). Diakses pada tanggal 29 April 2016. Tersedia di_ http:/www.kompasiana.com/akrie_style/globalisasipendidikan_5500dc29a333117c6f512447\#_ftn1

[3] Fitri, A.S. 2011. Nalar Kritis Mahasiswa, dalam Jurnal Inovasi Pendidikan. FKIP Universitas Muhammadiyah Malang. Vol. 1 No. 2 November 2015.

[4] Lee, Sungyoung Lee \& Lim, Sora. Gamification on Phrase Building Training Application, International Journal of Software Engineering and Its Applications. Vol. 9, No. 3, p. 184.

[5] Putra, Panca O. Hadi dan Zainal Hasibuan. 2015. E-Business Framework Small and Medium Entreprises: A Critical Review.

[6] Dewantara, Caesar Fattah Citra Dewantara. 2015. Analisis Dampak Penggunaan Situs Bukalapak Terhadap Perilaku Pembelian Pada Komunitas Samarinda Photographer. Tersedia di http //ejournal.ilkom.fisip-unmul.ac.id/site/wpcontent/uploads/2015/06/jurnal\%20cesar\%20done\%20untuk\%20dprint\%20selesai\%20j umat\%20(06-26-15-03-51-42).pdf

[7] Setiawan, Budi. Karya Ilmiah 2012. E-Business yang Dilakukan Oleh SAP. STMIK AMIKOM Yogyakarta.

[8] Romadhon, Wahyu Aji Cahya. 2013. Perdagangan Online Pada Situs Tokobagus Dalam Perspektif Tekno Ekonomi. Tersedia di. http//journal.unair.ac.id/filerPDF/Wahyu\%20Aji\%20Cahya\%20Romadhon.pdf

[9] Rahardja, Untung. Qurotul Aini dan Desi Sartika. CCIT Journal 2014. Build A Business To Consumer Online Store Using Airzone Content Management System. Perguruan Tinggi Raharja.

[10] Aani dan Cahyo Anggoro Seto. CCIT Journal 2015. Content Management System ZPreneur In Support Of Entrepreneurship iLearning At Perguruan Tinggi Raharja. Perguruan Tinggi Raharja.

[11] Ginting, Elizaandyni. 2013. Aplikasi Penjualan Berbasis Web ( E-Commerce) Menggunakan Joomla Pada Mutiara Fashion. Tugas Akhir Universitas Widyatama : Bandung.

[12] Harahap, Eka Purnama. 2015. Analisa Manajemen Gamifikasi ZPreneur Sebagai Inovasi Pembelajaran Pada Perguruan Tinggi. Perguruan Tinggi Raharja. 